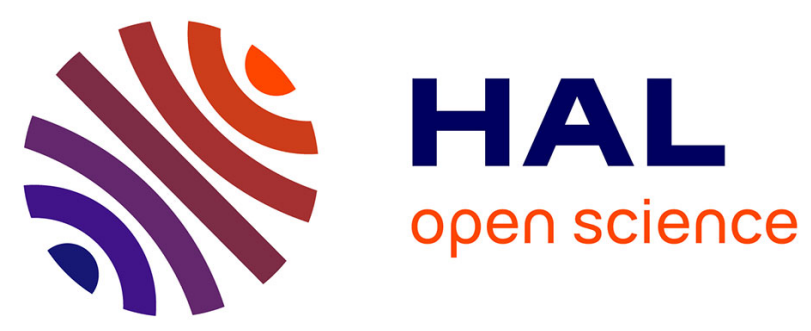

\title{
Aerosol synthesis of thermally stable porous noble metals and alloys by using bi-functional templates
}

Mateusz Odziomek, Mounib Bahri, Cédric Boissière, Clément Sanchez, Benedikt Lassalle-Kaiser, Andrea Zitolo, Ovidiu Ersen, Sophie Nowak, Cédric Tard, Marion Giraud, et al.

\section{To cite this version:}

Mateusz Odziomek, Mounib Bahri, Cédric Boissière, Clément Sanchez, Benedikt Lassalle-Kaiser, et al.. Aerosol synthesis of thermally stable porous noble metals and alloys by using bi-functional templates. Materials Horizons, 2020, 7 (2), pp.541-550. 10.1039/C9MH01408J . hal-02617368

\section{HAL Id: hal-02617368 \\ https://hal.sorbonne-universite.fr/hal-02617368}

Submitted on 25 May 2020

HAL is a multi-disciplinary open access archive for the deposit and dissemination of scientific research documents, whether they are published or not. The documents may come from teaching and research institutions in France or abroad, or from public or private research centers.
L'archive ouverte pluridisciplinaire HAL, est destinée au dépôt et à la diffusion de documents scientifiques de niveau recherche, publiés ou non, émanant des établissements d'enseignement et de recherche français ou étrangers, des laboratoires publics ou privés. 


\section{Aerosol synthesis of thermally stable porous noble metals and alloys by using bi-functional templates}

Received 00th January 20xx, Accepted 00th January 20xx DOI: $10.1039 / \times 0 \times x 00000 x$

\author{
Mateusz Odziomek, ${ }^{\mathrm{a}}$ Mounib Bahri, ${ }^{\mathrm{b}}$ Cedric Boissiere, ${ }^{\mathrm{a}}$ Clement Sanchez, ${ }^{\text {a Benedikt Lassalle- }}$ \\ Kaiser, ${ }^{\mathrm{c}}$ Andrea Zitolo, ${ }^{\mathrm{c}}$ Ovidiu Ersen, ${ }^{\mathrm{b}}$ Sophie Nowak, ${ }^{\mathrm{d}}$ Cedric Tard, ${ }^{\mathrm{e}}$ Marion Giraud, ${ }^{\mathrm{d}}$ * Marco \\ Faustini, ${ }^{a}$ * Jennifer Peron ${ }^{d} *$
}

Porous noble metal nanostructures providing high surface areas and large pore volumes are attractive for numerous applications especially catalysis. However, the synthesis of such architectures with nanoscale features is challenging because of i.e high surface energy. Previous reports are based on multi-step synthetic approaches with low yield thus not compatible with industrial scale. Herein, we demonstrate that hierarchical nanostructured noble metals and alloys, with thermal stability up to $800^{\circ} \mathrm{C}$, can be fabricated by a high throughput, green and straightforward aerosol-assisted synthesis using bi-functional reducing templates. We unravel the reduction mechanism at the solid/solid interface at the single-particle level using state-of-the-art techniques such as in situ Transmission Electron Microscopy, in situ synchrotronbased X-ray absorption spectroscopy. We propose a mechanism based on a radical process thermally triggered by the depolymerization of organic components. From a fundamental point of view, this study sheds light on the reduction processes of noble metals in the presence of organic compounds with important fundamental implications for catalysis and electrocatalysis.

\section{Introduction}

Noble metals exhibit excellent catalytic properties, ${ }^{1}$ used for instance in hydrogenation, ${ }^{2}$ water splitting ${ }^{3,4}$ or fuel cells. ${ }^{5,6}$ However, their high cost and scarcity fuel the research on novel architectures increasing the performance, reducing the cost and increasing the stability of the materials. The

Sorbonne Université, CNRS, Collège de France, PSL Research University, Laboratoire Chimie de la Matière Condensée de Paris, LCMCP, 4 Place Jussieu, F75005, Paris, France

b. IPCMS-UMR 7504 CNRS, Université de Strasbourg, 23 Rue du Loess, BP 43-67034, Strasbourg Cedex 2, France

Synchrotron SOLEIL, L'orme des Merisiers, Saint-Aubin, 91192 Gif-sur-Yvette, France

d. Université de Paris, ITODYS, CNRS, UMR 7086, 15 rue J-A de Baï, F-75013 Paris, France

LCM, CNRS, Ecole polytechnique, Institut Polytechnique de Paris, France

Electronic Supplementary Information (ESI) available: [details of any supplementary information available should be included here]. See DOI: $10.1039 / x 0 x \times 00000 x$ optimized structuration of these catalysts provides a high surface-to-volume ratio maximizing the accessibility of the active sites and reducing the amount of matter, large pore volume facilitating mass transport and in the case of electrocatalysis possibly ensures electron transport. ${ }^{7}$ Materials showing hierarchical structuration with multiscale porous structure are particularly attractive for applications involving interfacial processes thanks to their high surface area and 3D porous network. ${ }^{8}$ Indeed, the rational design of nanoscale microstructures plays a key role in the development of advanced functional materials. ${ }^{9-11}$.

Synthesis of such porous architectures is not trivial, especially for noble metals which exhibit high surface energy. Moreover, nanostructured noble metals very often experience loss of morphological and structural properties upon chemical and thermal treatment. ${ }^{12}$ Although reported in the literature, the synthesis of porous nanostructured noble metals has been limited to multi-step, solution based syntheses at small labscale and thus incompatible with industrial processes. ${ }^{13,14}$ It is therefore critical to develop methods that couple chemistry with advanced processing so as to fulfill the concept of integrative chemistry ${ }^{15-17}$ and offer a direct transfer pathway to a practical technology, which is often overlooked in favour of maximized performances. ${ }^{18}$

One of such methodology is aerosol-assisted synthesis. Well known for the very large scale drying of milk and coffee, it is also widely applied in industry especially for application in catalysis; indeed, it is a major processing method for the production of catalysts with more than 1400 patents on this topic. ${ }^{19}$ In that case, the production rate ranges from a few tens of grams per hour at lab scale ${ }^{20}$ to several hundreds of $\mathrm{kg}$ per hour at industrial scale. ${ }^{21}$ Classically, it involves atomisation of precursor solution, as metal salt, which undergoes rapid precipitation and decomposition at high temperature. This ensures high homogeneity of the formed solid particles. Aerosol processing was further combined with sol-gel chemistry and evaporation-induced self-assembly (EISA) allowing for the development of a wide range of porous materials, ${ }^{22,23}$ as recently reviewed by Debecker et al. ${ }^{19}$ In this 
particular synthesis process, the sol-gel reaction is confined in atmosphere or even in air, i.e. without the use of a reducing
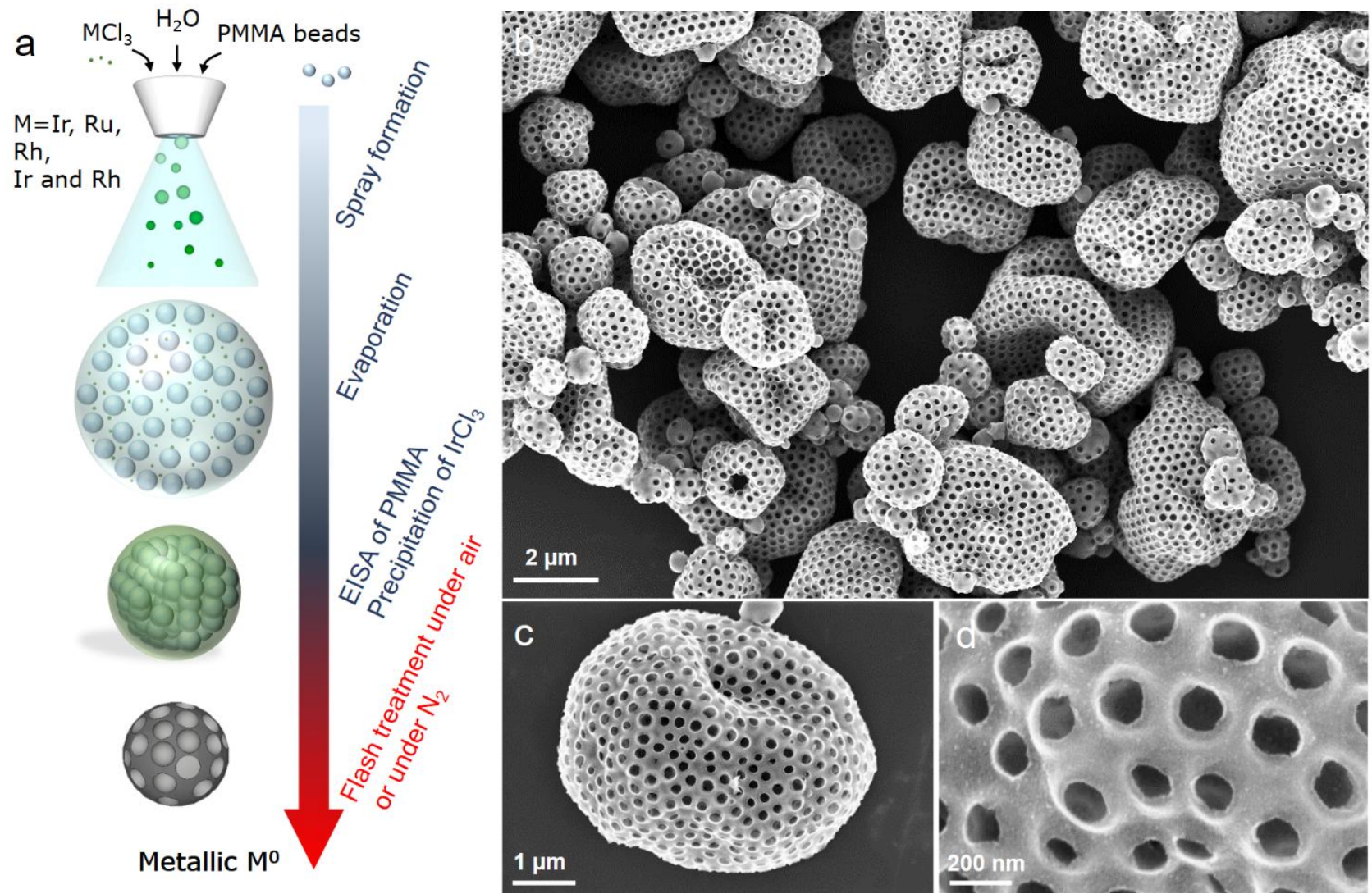

Figure 1. Synthesis and morphology of ultraporous Ir particles. (a) schematic picture of the synthesis process; (b-d) SEM images of reduced Ir samples after calcination at $450{ }^{\circ} \mathrm{C}$ in $\mathrm{N}_{2}$ atmosphere.

\section{evaporating}

microdroplets, limiting the size of particles. The use of organic self-assembling templates, such as micelles or latex beads, which can be removed by a simple thermal treatment allows to create the porous network. Although, this approach has been used for the synthesis of a wide range of porous compounds such as metal oxides, ${ }^{24}$ chalcogenides ${ }^{25}$ or metal organic frameworks, ${ }^{26}$ the preparation of noble metals (pure metal or alloys) by this method has never been reported, to the best of our knowledge.

In this contribution, we extend the composition threshold of aerosol-made materials to metallic materials and alloys to obtain ultraporous architectures. Considering their relevance for catalytic application, we focus on noble metals such as Ir, $\mathrm{Ru}, \mathrm{Rh}, \mathrm{Pt}$ and Pd. The materials are shaped in one step as macroporous spheres by aerosol. In order to avoid expensive treatment under reducing atmosphere (undesired in industrial processes), we propose a strategy that takes the advantage of the dual role of polymeric beads that act simultaneously as templating and reductive agents. Indeed, in this configuration, the porous metallic structures are obtained at the solid state through calcination at moderate temperature in nitrogen atmosphere. To unravel this chemical mechanism, we use a set of in situ experiments including X-ray absorption spectroscopy (XAS), high resolution scanning transmission electron microscopy (HR STEM) and thermogravimetric analysis (TGA) coupled with analytical techniques to follow simultaneously structural, microstructural and chemical transformations. Unlike previous reports, we assign the reduction of the metal salt and the metal formation under non-reductive or even oxidative atmosphere to a radical process thermally triggered by the depolymerization of organic components.

This water-based, green and scalable approach opens important perspectives in terms of synthesis of noble metals compounds with high surface area and tailored architecture. Besides, this study sheds light on the reduction processes of noble metals in the presence of organic compounds with important fundamental implications for catalysis and electrocatalysis.

\section{Results and discussion}

Synthesis of ultraporous metallic particles 
a

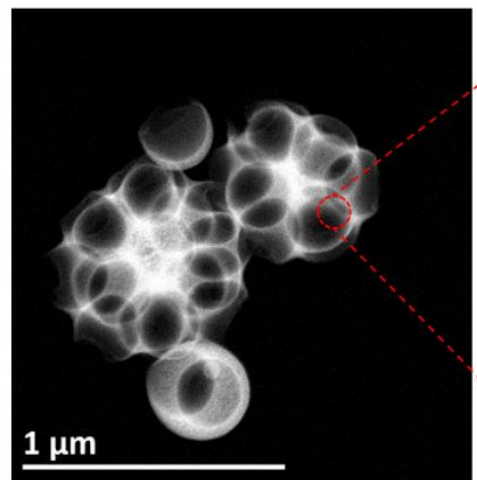

b

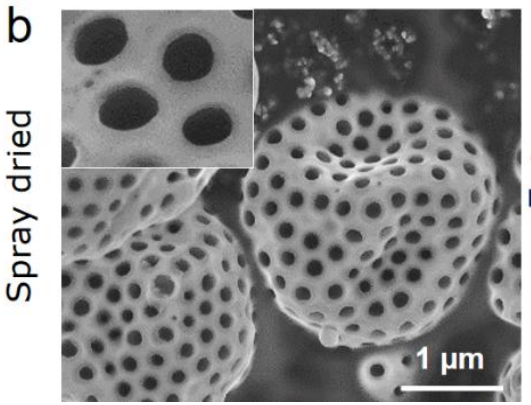

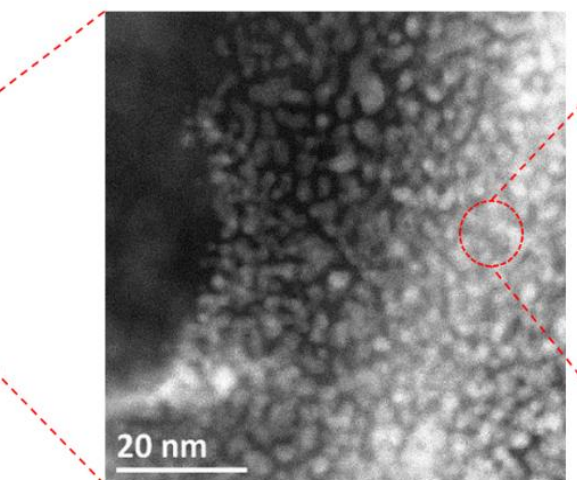
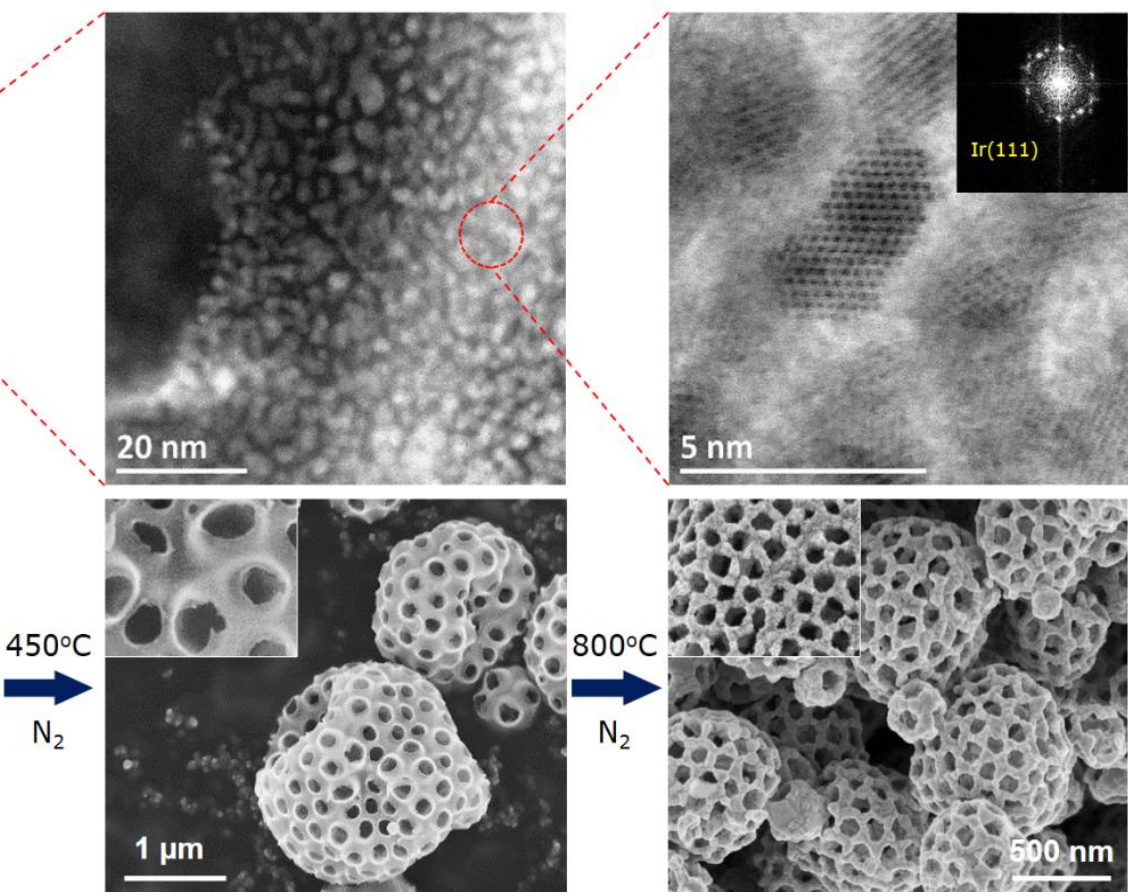

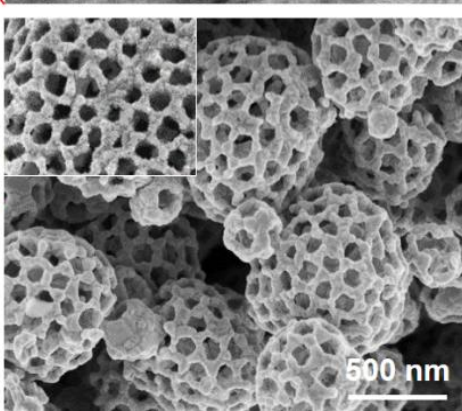

Figure 2. Electron microscopy of porous iridium. (a) STEM-HAADF and HR STEM bright field images of samples calcined at $450{ }^{\circ} \mathrm{C}$ in nitrogen atmosphere, the inset picture shows FFT of the corresponding image confirming the presence of the well-crystallized metallic Ir; (b) SEM images of products as spray-dried, calcined at $450{ }^{\circ} \mathrm{C}$ and calcined at $800^{\circ} \mathrm{C}$ under nitrogen.

The synthetic mechanism is first exemplified with the case of metallic iridium. This material is indeed of paramount importance for its activity in the oxygen evolution reaction. ${ }^{27,28}$ A schematic picture illustrating the synthetic route towards ultraporous iridium nanostructures is shown in Figure 1a (the detailed description is presented in SI). Briefly, iridium chloride is dissolved in water together with monodispersed PMMA latex beads ( $c a .270 \mathrm{~nm}$ ). The spray drying of this solution forms droplets in which the latex beads self-assemble through an evaporation-assisted process, and the iridium species precipitate around the polymer spheres forming organicinorganic hybrid spheroidal structures. This material is further calcined to remove the polymeric templating agent and form an inorganic porous network.

According to the literature, ${ }^{19}$ spray-drying of transition metal salts involves classical sol-gel chemistry via hydrolysis of the metal salt and further condensation during the evaporation process. The emerged hydrated inorganic network is subsequently converted into the corresponding oxide upon calcination in air. Indeed, in the case of $\mathrm{Ir}$, the oxide phase is obtained at $450{ }^{\circ} \mathrm{C}$, although only if a low heating rate is applied $\left(<1.5^{\circ} \mathrm{C} / \mathrm{min}\right) .^{24}$

Surprisingly, when heat-treating the sample at a fast heating rate in air at $450{ }^{\circ} \mathrm{C}\left(>20^{\circ} \mathrm{C} / \mathrm{min}\right)$, metallic porous particles of $\mathrm{Ir}$ are obtained rather than oxide. The formation of zero valent iridium occurs also when the calcination of the hybrid material is carried out in an inert atmosphere (nitrogen for instance). On the contrary, when $\mathrm{IrCl}_{3}$ precursor is dissolved alone, dried in the oven and calcined in the same conditions, only an amorphous product is obtained. The same experiment performed with the addition of PMMA latex beads again forms metallic iridium (Figure S1).

The formation of metallic $\mathrm{Ir}$ along with $\mathrm{IrO}_{2}$ has been reported upon calcination of iridium salts in air. Osaka et al. observed the formation of metallic Ir films upon heating of iridium ethoxide in air at $350{ }^{\circ} \mathrm{C}^{29}$ Later, the $\mathrm{Ir}^{0}$ was at least partially converted into $\mathrm{IrO}_{2}$ with higher calcination temperature. On the contrary, $\mathrm{H}_{2} \mathrm{IrCl}_{6} * 6 \mathrm{H}_{2} \mathrm{O}$ yielded mostly $\mathrm{IrO}_{2}$ species. The authors attributed the formation of metallic iridium to its large electronegativity inducing a high covalency of $\mathrm{Ir}-\mathrm{OCH}_{2} \mathrm{CH}_{5}$ bond and hence a small hydrolysis rate $\mathrm{k}_{\mathrm{h}}$ favoring the precipitation of metallic iridium. Similar observations have been made in several recent publications concerning the preparation of $\mathrm{IrO}_{2}$ nanowires or nanofibers by electrospinning. ${ }^{30-33}$ Calcination of electrospun fibres from $\mathrm{IrCl}_{3}$ mixed with PVP in DMF or DMF/ethanol solution yielded a mixture of $\mathrm{IrO}_{2}$ and $\mathrm{Ir}^{0}$ or even pure $\mathrm{Ir}^{0}$ at $350{ }^{\circ} \mathrm{C}^{31}$ and 400 ${ }^{\circ} \mathrm{C} .{ }^{32}$ Even if the formation of noble metal particles in an oxidative atmosphere has been reported in several studies, the reduction mechanism remains unclear.

\section{Microstructural analysis by electron microscopy}

In order to investigate the microstructural aspect of the materials and for a deeper understanding of the mechanisms leading to the formation of metal, a series of electron microscopy experiments was performed. Scanning electron microscopy (SEM) images confirm that the product is made of macroporous spheroidal particles, as usually expected for materials prepared by spray-drying, ${ }^{34}$ with sizes ranging from 0.3 to $3 \mu \mathrm{m}$ (Figure $\mathbf{1 b}$-d). In calcined materials, the pores are 
uniformly organised throughout the particles in quasihexagonal arrays, which is a consequence of using highly monodispersed latex beads (Figure S2-S3). Larger spheres (over $1 \mu \mathrm{m}$ ) are hollow with the shell thickness corresponding to one or two layers of PMMA beads (Figure S4). STEM images reveal that the walls of the spheres are built by very small Ir nanoparticles (NPs) of a few $\mathrm{nm}$ (Figure 2a). Further HR-STEM confirmed the face centred cubic $(f c c)$ structure of the NPs by the presence of (111) crystallographic planes, which are
Absorption Fine Structure (EXAFS) provides important insights on the local environment of the atoms investigated. The method was used to characterize the iridium oxidation state and its atomic environment upon calcination under $\mathrm{N}_{2}$ or air for the spray-dried hybrid samples as well as for commercial iridium salts. The results are presented in Figure 3 along with in situ STEM-Energy-dispersive $\mathrm{X}$-ray spectroscopy (EDX) mapping of a single particle before and after calcination at 450 ${ }^{\circ} \mathrm{C}$ (Figure 3a). The latter shows the transformation to metal
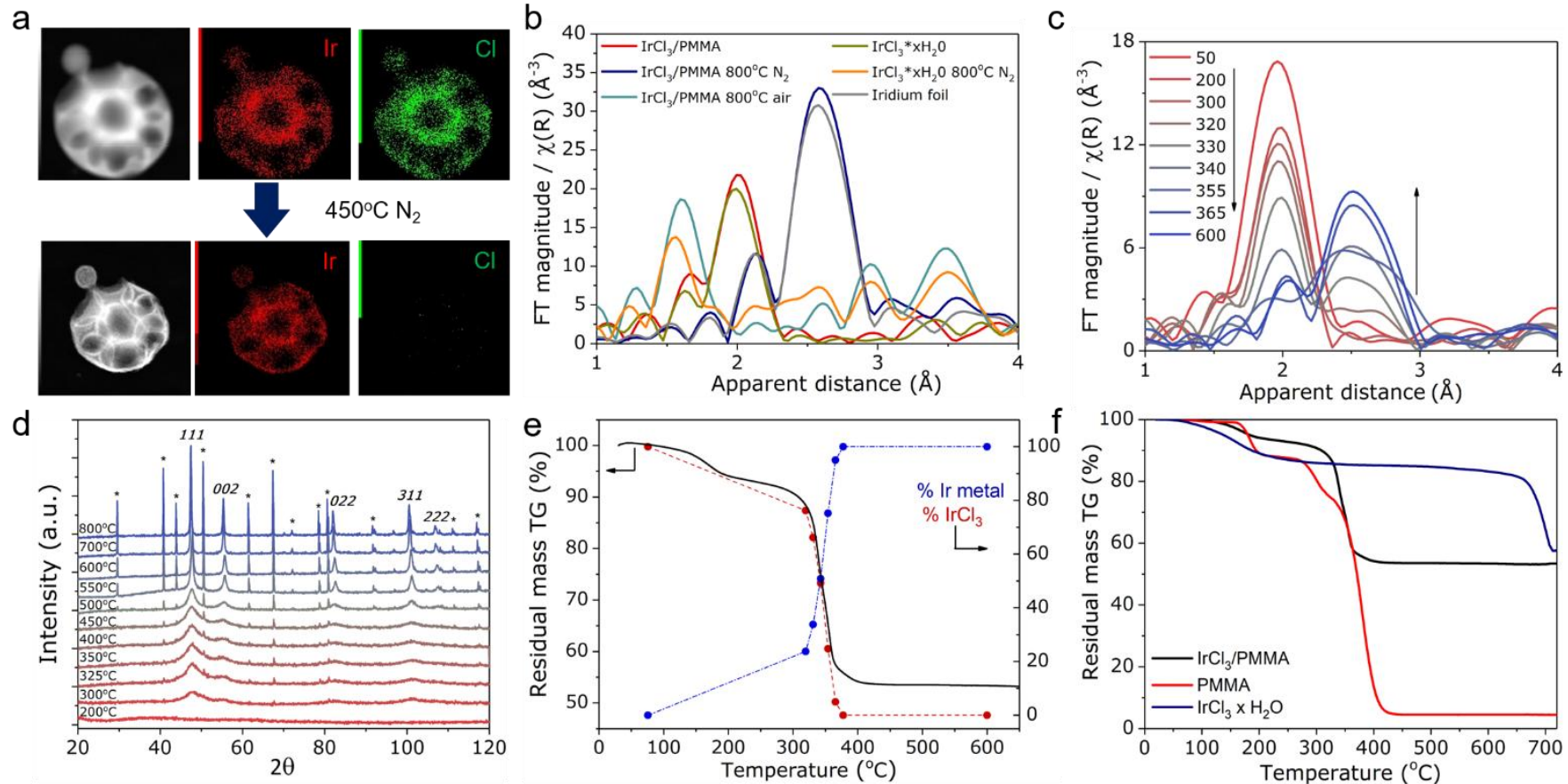

Figure 3. The evolution of the structure during thermal treatment. (a) in situ STEM-EDX mapping of the same particle before and after calcination at $450{ }^{\circ} \mathrm{C}$; (b) FT-EXAFS spectra of the spray-dried product and the $\mathrm{IrCl}_{3}$ precursor thermally treated under different conditions and compared to a metallic iridium foil; (c) in situ FT-EXAFS spectra of the spray dried product during thermal treatment in nitrogen atmosphere; (d) in situ XRD of the spray-dried hybrid particles during calcination in nitrogen. The appearance of peaks at high temperatures marked with stars is associated with the silicon substrate which becomes more and more exposed upon shrinkage of the investigated layer; (e) TGA combined with molar percentage of Ir metal and $\mathrm{IrCl}_{3}$ calculated from in situ XANES linear combination fittings; dashed lines serve as eye-guides, (f) TGA curves of PMMA, IrCl 3 precursor and spray-dried hybrid particles.

characteristic of metallic Ir (Figure 2a inset).

The initially formed hybrid particles keep their shape and overall structuration upon calcination at $450{ }^{\circ} \mathrm{C}$ despite the thermal decomposition of the polymer leaving empty voids, and crystallization of Ir NPs. (Figure 2b). The increase in calcination temperature to $800{ }^{\circ} \mathrm{C}$ further induces growth and sintering of the NPs, while preserving the remarkable macroporous spheroidal morphology. These results highlight that the synthesized nanostructures are robust and can adjust themselves to a different degree of crystallization and sintering.

\section{Chemical evolution upon calcination: in situ analyses}

For a better understanding of the role of PMMA and the mechanism of formation of the metallic phase, we resorted to in situ XAS combined with in situ X-ray diffraction (XRD) and TGA. While the X-ray Absorption Near Edge Structure (XANES) signal gives information on the oxidation state of the considered element, the analysis of the Extended X-Ray and the complete loss of chlorine atoms.

Figure $\mathbf{3 b}$ shows the Fourier transforms (FT) of the Ir $\mathrm{L}_{111}{ }^{-}$ edge EXAFS spectra of the $\operatorname{IrCl}_{3} / \mathrm{PMMA}$ hybrids and the commercial $\mathrm{IrCl}_{3} * \mathrm{xH}_{2} \mathrm{O}$ both fresh and after calcination at 800 ${ }^{\circ} \mathrm{C}$ under air or under $\mathrm{N}_{2}$ flow, together with that of a metallic Ir foil as the reference. The corresponding XAS spectra (normalized to an edge-jump of 1 ) are presented in SI (Figure S5a). The FT-EXAFS signals of Ir ions in the spray-dried hybrid material and in the commercial $\mathrm{IrCl}_{3}$ precursor are very similar. Both exhibit a strong peak at $\mathrm{R}^{\prime}=2.0 \AA$, assigned to the first $\mathrm{Ir}$ $\mathrm{Cl}$ coordination shell. ${ }^{35}$ The first main conclusion of these experiments is that, unlike classical sol-gel processes of transition metals, the iridium precursor of the inorganic network stays in its initial chloride form. It is not surprising since the hydrolysis of iridium chloride in the applied conditions is rather scarce because of the high electronegativity of Ir. In the solution, most of chloride ions remain bounded to the metal atoms due to the high covalent character of the $\mathrm{Ir}-\mathrm{Cl}$ bonds. This implies that the Ir-O bond 
rather forms during the thermal treatment. The calcination at $800{ }^{\circ} \mathrm{C}$ under oxygen-free atmosphere transforms the commercial hydrated $\mathrm{IrCl}_{3}$ salt into iridium oxide as evidenced by its FT-EXAFS spectrum showing the Ir-O peak of $\mathrm{IrO}_{2}$ (peak at apparent distance $R^{\prime}=1.6 \AA$ ) (Figure 3b). The oxygen atoms are certainly provided by water molecules initially present. Unlike for pure iridium salt, the FT-EXAFS spectrum of the hybrid particles reveals that the thermal treatment in oxygenfree atmosphere induces the formation of metallic iridium as evidenced by the presence of peaks characteristic of Ir-Ir distances at $R^{\prime}=2.5 \AA$ (Figure $3 b$ ) matching that of a metallic foil. Finally, when air is flown through the hybrid sample during calcination at $800{ }^{\circ} \mathrm{C}$ (with a heating ramp of $5^{\circ} \mathrm{C} / \mathrm{min}$ ), iridium oxide is obtained. These results underline the crucial role of PMMA in the formation of metallic iridium.

The hybrid material structure evolution was followed as a function of temperature by performing in situ XAS and XRD measurements during calcination, which results are shown in the Figures $\mathbf{3 c}$ and $\mathbf{3 d}$ respectively. In the FT-EXAFS spectra (Figure 3c), we observe that the Ir local environment continuously evolves upon heating (corresponding XAS spectra are shown in the Figure $\mathbf{S} 5 \mathbf{b}$ ). The peak at $R^{\prime}=2.0 \AA$ assigned to Ir-Cl atomic distances continuously decreases while, above 300 ${ }^{\circ} \mathrm{C}$, a new peak emerges at $\mathrm{R}^{\prime}=2.5 \AA$ which corresponds to the Ir-Ir distance in metallic Ir. This suggests that the spray-dried precursor is directly transformed into metallic Ir without any intermediate Ir species. The formation of the new phase is in agreement with the appearance of peaks characteristic of the Ir $f c c$ structure on the X-ray diffractogramms (Figure $3 \mathbf{d}$ ). Between 300 and $500{ }^{\circ} \mathrm{C}$, broad XRD peaks indicate very small size of crystallites as confirmed by TEM observation. Peaks sharpen with further calcination as a consequence of NPs growth.

The molar fraction of the spray-dried $\mathrm{IrCl}_{3}$-like precursor and metallic Ir species throughout the calcination was calculated by linear combination fitting (LCF) of the Ir $\mathrm{L}_{111}$-edge XANES spectra (see corresponding spectra and details in the $\mathrm{SI}$ file - Figure S5b). ${ }^{35}$ The transition of $\mathrm{IrCl}_{3}$ to $\mathrm{Ir}$ metal starts slightly below $300{ }^{\circ} \mathrm{C}$ and finishes at ca. $370{ }^{\circ} \mathrm{C}$. The correlation of this result to TG analysis shows that the transition occurs precisely in the temperature range of a strong mass loss detected by TGA (Figure 3e). Interestingly, only one significant mass loss is observed for both metal chloride and PMMA meaning that they decompose simultaneously. However, the same TG experiment performed separately for PMMA latex beads and $\mathrm{IrCl}_{3}$ hydrate revealed that both compounds decompose at different temperatures as indicated in Figure $\mathbf{3 f}$. In the presence of PMMA, $\mathrm{IrCl}_{3}$ loses chloride ions at $c a .300$ ${ }^{\circ} \mathrm{C}$, i.e. at a much lower temperature than that of pure $\operatorname{IrCl}_{3}$ (ca. $650{ }^{\circ} \mathrm{C}$ ), highlighting the critical role of PMMA in the decomposition of $\mathrm{IrCl}_{3}$. To understand the mechanisms driving this peculiarity, the gaseous products generated during calcination have been analysed by Fourier-transform infrared spectroscopy (FTIR) and coupled gas chromatography massspectrometry (GC-MS).

TGA of radically polymerized PMMA is very characteristic with three weight losses starting at $160{ }^{\circ} \mathrm{C}, 270{ }^{\circ} \mathrm{C}$ and 320
${ }^{\circ} \mathrm{C}^{36}$ In each step, a homolytic cleavage of C-C bonds occurs, creating radical species. The first to break, between 160 and $320{ }^{\circ} \mathrm{C}$, are the least stable bonds in "defected" parts, such as head-to-head groups and unsaturated end-groups (Figure S6). The main decomposition pathway starts at $320^{\circ} \mathrm{C}$, through the random scissoring of the polymer backbone. Subsequent depropagation of polymeric radical species allows monomer molecules to be recovered. ${ }^{36}$ Indeed, the FTIR and MS spectra of volatile products at each decomposition step correspond to methyl methacrylate (MMA), or products of its own decomposition in the case of MS (Figure S7) confirming the depolymerisation mechanism. 6 wt.\% of the PMMA sample remains as a solid residue after calcination at $800{ }^{\circ} \mathrm{C}$ in the absence of oxygen (Figure 3f) due to alternative decomposition pathways leading to the formation of char.

In the case of the $\mathrm{IrCl}_{3}$ /PMMA hybrids, the mass loss observed below $200{ }^{\circ} \mathrm{C}$ is associated with the desorption of water. The first step of PMMA decomposition (scissoring of head-to-head groups) is much less pronounced compared to the pure polymer (Figure S8-S9). It probably partially occurs during the spray drying process $\left(220^{\circ} \mathrm{C}\right)$. The main mass loss, starting at ca. $260{ }^{\circ} \mathrm{C}$, presumably begins similarly to pure PMMA by scissoring of unsaturated end-groups and is continued by random scissoring as indicated by the detection of monomeric species by both FTIR and MS (Figure S8-59). The generated radicals either undergo depolymerisation involving expulsion of MMA monomers, as detected by both FTIR and $\mathrm{MS}$, or interact with $\mathrm{IrCl}_{3}$ intercepting chlorine (Figure 3a) to form $\mathrm{HCl}$ and $\mathrm{CH}_{3} \mathrm{Cl}$ as demonstrated by an emerging series of peaks between 3200 and $2800 \mathrm{~cm}^{-1}$ in the FTIR spectrum and by MS (Figure S8-S9). The detection of these species is a direct evidence of the interaction between $\mathrm{IrCl}_{3}$ and PMMA during thermal treatment. The evolution of $\mathrm{HCl}$ and $\mathrm{CH}_{3} \mathrm{Cl}$ is preceded by the first step of PMMA depolymerisation, while the second step is slightly retarded. This might suggest that the first created radicals trigger $\mathrm{IrCl}_{3}$ reduction. According to previously reported studies on the effect of transition metals on the depolymerisation of PMMA, ester groups coordinate to hard acids (such as $\mathrm{Ir}^{3+}$ ). ${ }^{37}$ This interaction is supposed to facilitate the release of $\mathrm{Cl}$ atoms that subtract hydrogen atoms from the organic chain. As reported for $\mathrm{PMMA}_{-}-\mathrm{CrCl}_{3}$ mixtures, ${ }^{38}$ and in our case such coordination probably occurs at higher temperatures since no peaks corresponding to carboxylic group coordinated to the metal centre can be detected on FTIR spectra (Figure S10). The appearance of methyl chloride further implies the coordination of carboxyl group to the iridium which facilitates the cleavage of methyl radical, which captures chlorine. The analysis of the evolved gaseous products also shows the presence of $\mathrm{H}_{2} \mathrm{O}, \mathrm{CO}_{2}, \mathrm{CH}_{4}$ and $\mathrm{CO}$ (Figure S8). These compounds are generated by an

\section{The reduction pathway by radical depolymerisation correlated to in situ STEM}

Summarizing, the analysis of evolved gases during the calcination shows that the main products are $\mathrm{MMA}, \mathrm{HCl}$ and $\mathrm{CH}_{3} \mathrm{Cl}$. Since Ir itself may have a catalytic role in PMMA decomposition, ${ }^{39,40}$ it is very challenging to exactly predict the 


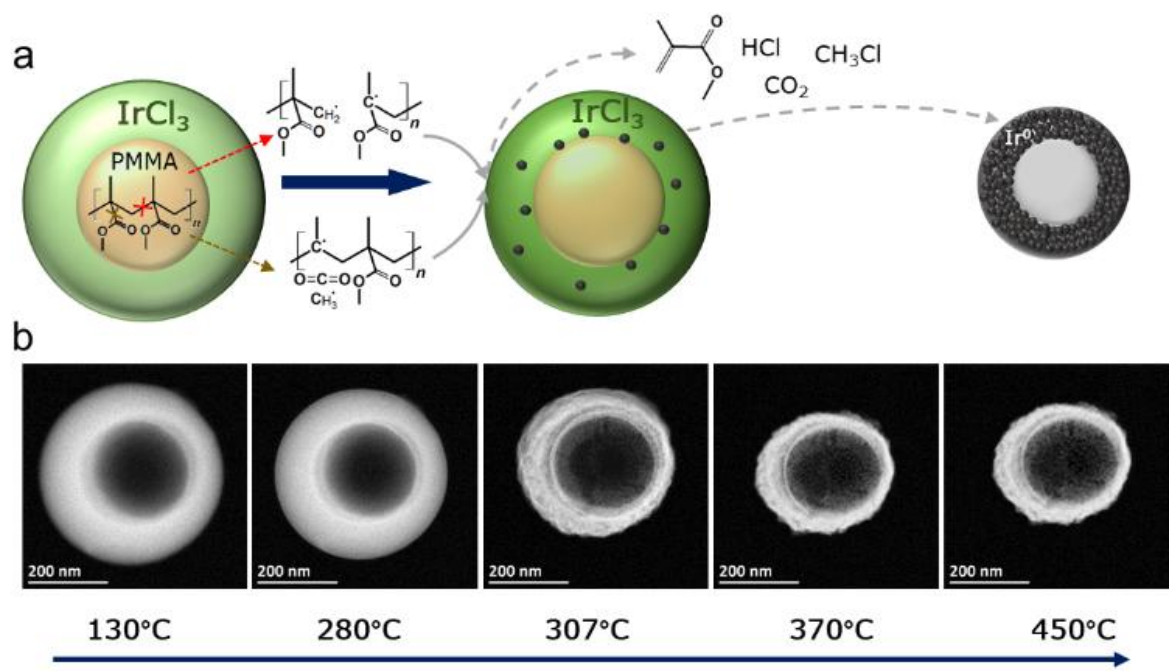

Figure 4. Illustration of the reduction and crystallization mechanism. (a) schematic picture showing the main process occuring during polymer-assisted reduction of $\mathrm{IrCl}_{3}$. (b) in situ STEM-HAADF images showing the microstructural evolution of a single latex bead covered with $\mathrm{IrCl}_{3}$ precursor during the calcination in nitrogen atmosphere.

reaction mechanism, especially at this relatively high temperature. In addition, the appearing CO may also serve as an efficient reducing agent of iridium halides through reductive carbonylation. ${ }^{41,42}$ Most likely, there are several different mechanisms occurring simultaneously. However, it is well-established in the literature (as discussed above) that the thermally-triggered homolytic cleavage with the formation of radicals is the main decomposition pathway of PMMA upon calcination under inert atmosphere. ${ }^{43,44}$ Taking into account the all above mentioned in situ analyses, simplified picture of PMMA-depolymerisation driven reduction can be proposed. (Figure 4a); it is correlated to the morphological evolution of particles tracked by in situ TEM in the Figure 4. In situ TEM allows to directly observe the crystallization of metallic NPs caused by the decomposition of PMMA. In order to visualise the reduction process at the organic-inorganic hybrid interface, a single latex bead covered with $\mathrm{IrCl}_{3}$ was selected for the experiment. Figure $\mathbf{4 b}$ shows STEM-HAADF images of the bead at different stages of the calcination. The particle shrinkage starts above $280{ }^{\circ} \mathrm{C}$. At first, the smooth surface becomes irregular and wrinkles because of the appearance of tiny NPs. At $370{ }^{\circ} \mathrm{C}$, the main transformation is completed and is followed by more discrete changes as Ir NPs grow. The temperatures of morphological transformation fit very well with the temperatures of chemical and structural changes, thus giving a full view on the process.

Finally, the presence of residual carbon was detected and characterized by Raman spectroscopy (Figure S11). The two broad bands peaking at 1583 and $1343 \mathrm{~cm}^{-1}$ are indicators of a disordered structure typically seen in amorphous carbon. ${ }^{45}$ The presence of carbon can account for the relatively high BET surface area of $123 \mathrm{~m}^{2} / \mathrm{g}$ measured by nitrogen adsorption (Figure S12). The presence of amorphous carbon can potentially be beneficial for enhanced adsorption of reactants in catalytic applications.

\section{Flash calcination in air}

As mentioned above, iridium metal can also be obtained when the hybrid sample is calcined under air. Indeed, when the sample is heated up to $450{ }^{\circ} \mathrm{C}$ at a fast rate $\left(>20{ }^{\circ} \mathrm{C} / \mathrm{min}\right)$ and kept at this temperature for $10 \mathrm{~min}$, pure fcc metallic iridium is obtained according to XRD measurements (Figure 5a). This alternative way of calcination allows producing pure metals with the same structuration as the one obtained under $\mathrm{N}_{2}$ as seen on the SEM images (Figure 5b), but without the presence of carbon (Raman analysis does not show any peaks coming from carbon, Figure S11). In contrast to nitrogen calcined material, the Raman spectroscopy reveals peaks originating from Ir-O bonds, despite the XRD purity of the metal phase (Figure 5a). We assigned this behaviour to oxygen bounded to the iridium surface. After flash calcination in air, the crystallites are larger as reflected by sharper XRD peaks (2.2 to $11.8 \mathrm{~nm}$ calculated by Scherrer equation) and the morphology is slightly different (Figure $\mathbf{5 c}$ ). In this case the surface is rather granular compared to the smooth one observed in nitrogen-calcined sample. These differences are attributed to the lack of carbon which most likely delays NPs growth and sintering.

In order to further investigate the particles' surface, XPS
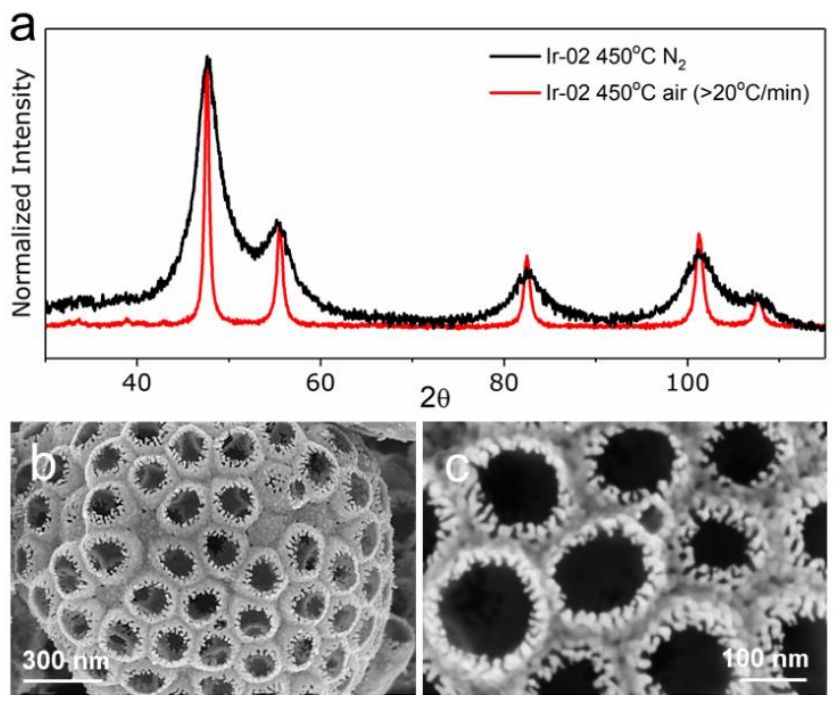

Figure 5. Hybrid particles flash calcined in air. (a) comparison of XRD patterns of samples calcined in nitrogen and air (with a high heating rate); $(b, c)$ SEM images of the 


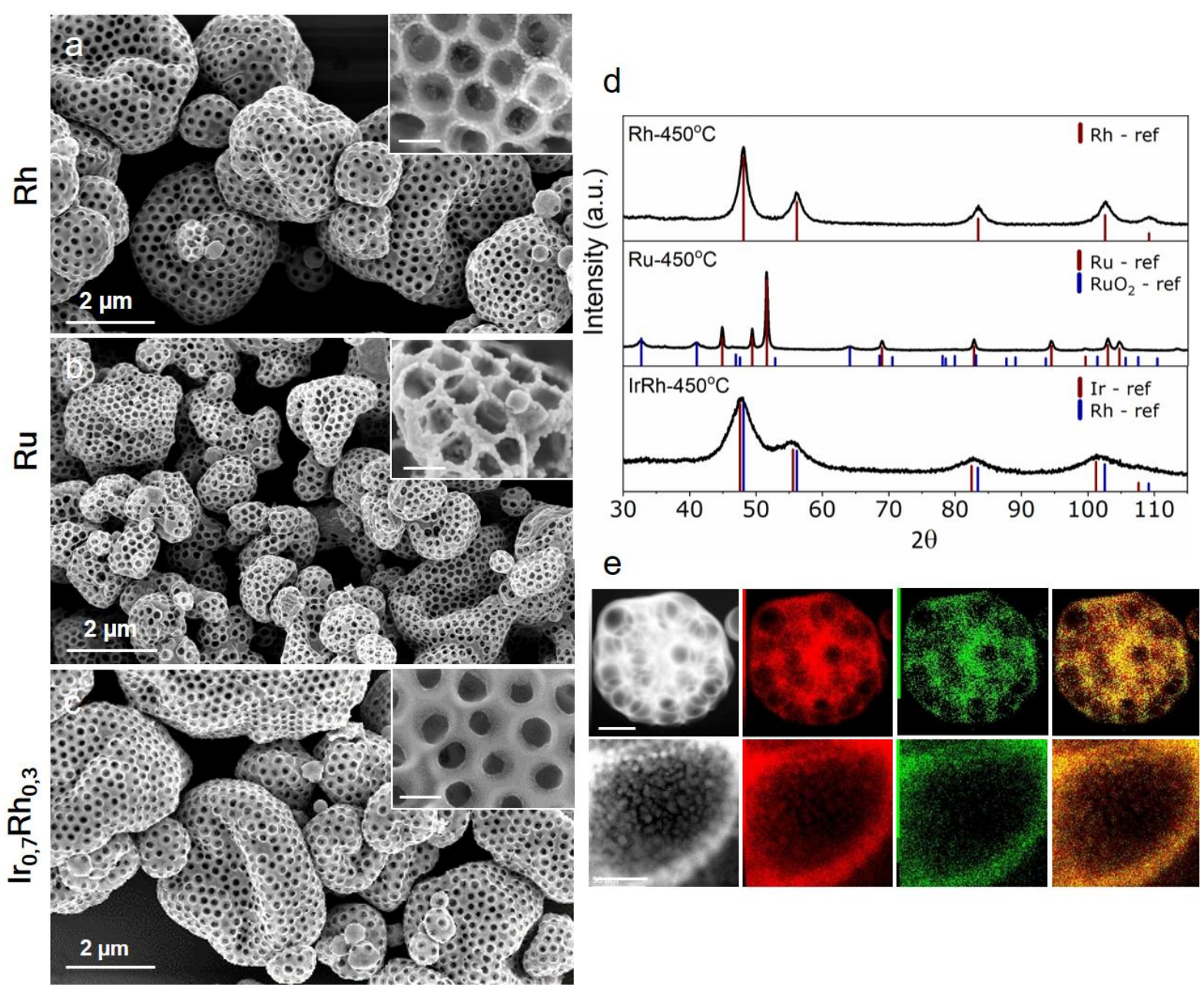

Figure 6. General synthesis approach for highly porous structures of noble metals. SEM pictures of different metals prepared by the same method: (a) ruthenium; (b) rhodium; (c) iridium-rhodium alloy with theoretical formula of $\mathrm{Ir}_{0,7} \mathrm{Rh}_{0,3}$ (scale bars in inset images - $200 \mathrm{~nm}$ ); (d) corresponding XRD patterns of samples calcined at $450{ }^{\circ} \mathrm{C}$ in $\mathrm{N}_{2}$; (e) STEM-EDX mapping in two different magnification with $\mathrm{Ir}$ (in red) and Rh (in green) and their overlay, scale bars: 300 and $50 \mathrm{~nm}$.

analysis was performed on both samples and compared to aircalcined particles with a slow heating ramp (Figure S13). As expected, the nitrogen-calcined sample shows intense peaks corresponding to $\mathrm{C}(1 \mathrm{~s})$ while in air-calcined samples this peak is at the level of impurities. For the sample calcined under $N_{2}$, in the Ir $4 \mathrm{f}$ region, only the two sharp peaks attributed to $4 f_{7 / 2}$ and $4 f_{5 / 2}$ in $\operatorname{Ir}(0)$ can be seen at 60.9 and $63.9 \mathrm{eV}$, respectively. On the contrary the slow air-calcined compound does not show contribution from $\operatorname{~Ir}^{0}$ and only the peaks characteristic of $\operatorname{Ir}(\mathrm{IV})$ can be observed at 61.9 and $64.9 \mathrm{eV}$ for $4 \mathrm{f}_{7 / 2}$ and $4 \mathrm{f}_{5 / 2}$, respectively. In the XPS spectrum of the fast air-calcined sample, both the contribution of $\operatorname{Ir}(0)$ and $\operatorname{Ir}(\mathrm{IV})$ can be deconvoluted from the $4 f_{7 / 2}$ and $4 f_{5 / 2}$ signals. Correlating XRD and XPS measurements, we can conclude that in the case of fast-air calcined samples, the core is metallic while the iridium located at the surface is at least partly oxidized.

Interestingly, the atomic ratio of $\mathrm{Ir} / \mathrm{Cl}$ calculated from XPS analysis shows strong variation between differently calcined samples, shown in Table 1. The slow calcination in air was the least effective for the decomposition of $\mathrm{IrCl}_{3}$, which strongly supports the radical mechanism. Under nitrogen, the polymer degrades exclusively through a depolymerisation mechanism generating radicals. Under inert atmosphere, the radicals have longer life-time which gives them more chance to interact with iridium salt and reduce it. In the case of calcination in air, the depolymerisation mechanism competes with oxidative decomposition of the polymer thus creating less radicals. In addition, the oxygen acts as a radical scavenger, which "deactivates" them. Similarly to calcination in inert atmosphere, high heating rates promote the depolymerisation mechanism and hence the generation of a large amount of radicals in a given volume allowing them to reduce the salt before its interaction with oxygen. On the contrary, low heating rates promote radical-free oxidative decomposition of the polymer, and, as a consequence the decomposition of $\mathrm{IrCl}_{3}$ occurs via thermal decomposition and oxidation without going through the metallic state. In fact, we observed that the formation of metal, oxide or their mixture is strongly related to the experimental setup used for calcination i.e. type of the oven, the amount of calcined sample and the gas flow rate. The formation of oxide is supported by a slow-heating rate and a high flow of oxygen/air directly through the sample. 
Table 1. Atomic ratio between $\mathrm{Ir}$ and $\mathrm{Cl}$ calculated on the basis of XPS analysis for samples calcined under different conditions

\begin{tabular}{|c|c|c|c|}
\hline $\begin{array}{c}\text { Calcination } \\
\text { parameters }\end{array}$ & $450^{\circ} \mathrm{C} \mathrm{N} \mathbf{2}$ & $\begin{array}{c}450^{\circ} \mathrm{C} \text { air } \\
\left(25^{\circ} \mathrm{C} / \mathrm{min}\right)\end{array}$ & $\begin{array}{c}450^{\circ} \mathrm{C} \text { air } \\
\left(2^{\circ} \mathrm{C} / \mathrm{min}\right)\end{array}$ \\
\hline $\begin{array}{c}\mathrm{Ir} / \mathrm{Cl} \text { atomic } \\
\text { ratio }\end{array}$ & 16,3 & 8,6 & 4,3 \\
\hline
\end{tabular}

\section{Generalization to other polymer templates as reducing agents}

The previous section described the role of the thermal depolymerisation of PMMA on the reduction of iridium chloride. This raises the question whether similar results can be obtained in the presence of other polymers or not. In fact, the thermal decomposition of polymers generally generates radicals because of homolytic cleavage of their backbones. Therefore, if the process is indeed radically-driven, the $\mathrm{IrCl}_{3}$ should be reduced in the presence of other polymers. We have extended our investigation to $\mathrm{IrCl}_{3}$ mixed with polystyrene (PS) latex beads. The XANES data were recorded as a function of the calcination temperature. These XANES spectra were fitted using LCF technique similarly to the analysis performed on the PMMA sample and the proportions between the spray-dried Ir precursor and the as-produced metallic Ir were plotted as a function of temperature along with the respective TGA analyses (see Figure S14). We observe the appearance of the Ir phase, however, in a different temperature range than in the case of PMMA. Similarly, the TG curves are correspondingly shifted and match well the XAS data.

The mechanism of PS thermal decomposition is similar to PMMA and occurs through a depolymerisation mechanism recovering mainly monomeric species. ${ }^{46}$ The recorded TGA for PS- $\mathrm{IrCl}_{3}$ shows a single mass loss starting at $380{ }^{\circ} \mathrm{C}$ which stays in good agreement with the temperature range of PS decomposition. ${ }^{46}$ Analogously to $\mathrm{PMMA}-\mathrm{IrCl}_{3}$, this single mass loss indicates that the decomposition of $\mathrm{IrCl}_{3}$ is triggered by the polymer degradation, but at a higher temperature. XAS data stay in good agreement with TGA (Figure S14a, b).

These data evidence that the main mass loss occurring in TG is concomitant to the transformation of $\mathrm{r}^{3+}$ into metallic $\mathrm{Ir}$ and this is the case for the two polymers. This proves that the reduction of iridium salt is triggered by the polymer decomposition generating radicals. According to these results, the temperature of salt-to-metal transition can be tuned very easily just by changing the polymer used.

\section{Generalization to other noble metals and alloys}

We also demonstrate that this single protocol is very versatile and allows preparing other noble metals with highly porous structures, e.g. Rh, Ru (Figure 6), Pt and Pd (Figure S15). In addition, the perfect mixing on atomic scale makes the method suitable for the synthesis of metal alloys as shown for the $\operatorname{Ir}_{0,7} \mathrm{Rh} \mathrm{h}_{0,3}$ alloy (Figure $6 \mathrm{c}-\mathbf{e}$ ).

The crystallization and crystal growth kinetics are slightly different depending on the metal considered as it can be seen on the X-ray diffractogramms (Figure 6d). After calcination at
$450{ }^{\circ} \mathrm{C}$ under $\mathrm{N}_{2}$, the crystallite size calculated from XRD are of $2.2 \mathrm{~nm}, 4.8 \mathrm{~nm}, 25.4 \mathrm{~nm}$ for $\mathrm{Ir}, \mathrm{Rh}$ and Ru, respectively, and of $1.8 \mathrm{~nm}$ for the Ir-Rh alloy. These differences are reflected on the SEM images (Figure 6a-c), where the morphology of the particles obtained at $450{ }^{\circ} \mathrm{C}$ under $\mathrm{N}_{2}$ varies from smooth for Ir to polycrystalline for $\mathrm{Ru}$. The situation for $\mathrm{Rh}$ is intermediate, and SEM images show a smooth surface "decorated" with crystallites. Concerning Pd and Pt, the metallic spherical and porous structures are also obtained (Figure S15), but with slightly different morphologies caused by the excessive growth of Pd metallic particles and the interaction of Pt and Pd salts with utilized latex particles (see Supplementary Information). As for Ir and $\mathrm{Rh}$, the diffraction patterns of $\mathrm{Pt}$ and $\mathrm{Pd}$ correspond to pure $f c c$; $\mathrm{Pt}$ and $\mathrm{Pd}$ nanoparticles size determined from XRD are 7.9 and $34.7 \mathrm{~nm}$, respectively. Unlike other noble metals, Ru crystallizes in the hexagonal compact (hcp) structure, and the metal is found along with a small percentage of $\mathrm{RuO}_{2}$. We observed that if $\mathrm{RuCl}_{3} / \mathrm{PMMA}$ hybrid particles were exposed to ambient humidity for an extended period after spray-drying, the amount of $\mathrm{RuO}_{2}$ was increased in the final product probably due to the fact that the $\mathrm{Ru}$ precursors are highly hygroscopic. Despite the distinct structure and size of the NPs, for $\mathrm{Ir}, \mathrm{Rh}$ as well as $\mathrm{Ru}$, the overall structuration of the material as macroporous micrometric beads remains unchanged indicating its good adaptability to crystallization and sintering as discussed above. Moreover, we showed in our previous work that metal oxide can be obtained as nanostructured microsphere from the same precursor by changing the calcination protocol. ${ }^{24}$ Finally, the distribution of $\mathrm{Ir}$ and $\mathrm{Rh}$ atoms in the alloy was investigated by STEM-EDX mapping (Figure 6e). It revealed that Ir and Rh atoms are very well distributed throughout the particles, without segregation, indicating that this method is also suitable for the preparation of highly porous homogeneous alloys.

\section{Conclusions}

In this work, we demonstrate for the first time that the aerosol synthesis can be extended to metallic materials shaped as porous microspheres. Combination of aerosol-processing, EISA and template-assisted reduction strongly simplifies the formulation of the process, which, unlike traditional synthesis strategy of porous noble metals, makes it very easily adaptable to industrial-scale production. The method is aqueous based, waste-free and highly versatile: it is applicable to various noble metals and alloys, the size of the pores can be tuned by changing the latex size, the noble-metal particle size can be simply tuned by changing the calcination temperature, the metal can be obtained with residual carbon or not depending on the calcination conditions.

In addition, by combining at wide set of in situ characterisation techniques, we provide a comprehensive understanding of the formation of noble metal particles under oxidative atmosphere starting from a metal salt and a polymeric agent. Broad and exhaustive microstructural and chemical analyses were used to demonstrate that the polymer 
not only acts as a porogen but also as reductive agent. It shed light on previous researches in which organometallic precursors or salts mixed with different polymers were found to produce metal under oxidative conditions. Since the thermal decomposition of the polymer triggers the transition from salt to metal, the temperature at which the metal phase is formed can be tuned very easily by changing the polymer used.

All of this demonstrates enormous versatility of this approach and can serve for the preparation of controlled porous structures with complex compositions such as multimetallic alloys. This represents an ideal playground for the exploration of new self-supported noble metals and alloys, with important implications in catalysis and electrocatalysis.

Further studies will focus on the development of novel polymeric templates with varying reduction potential and improved compatibility with certain metal salts. It can be realized by changing the polymer, adding a co-polymer or tuning the surface state. In addition, we are working to extend the scope of accessible metals to non-noble ones.

\section{Conflicts of interest}

There are no conflicts to declare.

\section{Acknowledgements}

The work of M.O. was financially supported by Collège de France. M.F. acknowledges the European Union's Horizon 2020 Programme (FP/2014-2020)/ERC Grant Agreement n.803220TEMPORE. The XAS experiments were performed on SAMBA beamline at Synchrotron Soleil (Proposal 20170222). We would like to acknowledge Guillaume Alizon for his assistance in the in situ XAS measurements, Alexandre Chevillot for performing TG-FTIR analysis and Janusz Partyka for TG-MS.

\section{References}

1 C. Zhu, D. Du, A. Eychmüller and Y. Lin, Chem. Rev., 2015, 115, 8896-8943.

2 W. Zang, G. Li, L. Wang and X. Zhang, Catal. Sci. Technol., 2015, 5, 2532-2553.

3 P. Li, M. Wang, X. Duan, L. Zheng, X. Cheng, Y. Zhang, Y. Li, Q. Ma, Z. Feng, W. Liu and X. Sun, Nat. Commun., 2019, 10, 1711.

4 C. Hu, L. Zhang and J. Gong, Energy Environ. Sci., DOI:10.1039/c9ee01202h.

5 Z. Liang, L. Song, S. Deng, Y. Zhu, E. Stavitski, R. R. Adzic, J. Chen and J. X. Wang, J. Am. Chem. Soc., 2019, 141, 96299636.

6 H.-J. Yin, J.-H. Zhou and Y.-W. Zhang, Inorg. Chem. Front., DOI:10.1039/C9QI00689C.

7 L. Liu and A. Corma, Chem. Rev., 2018, 118, 4981-5079.

8 M.-H. Sun, S.-Z. Huang, L.-H. Chen, Y. Li, X.-Y. Yang, Z.-Y. Yuan and B.-L. Su, Chem. Soc. Rev., 2016, 45, 3479-3563.

9 Z. Fang, Y. Wang, C. Liu, S. Chen, W. Sang, C. Wang and J. Zeng, Small, 2015, 11, 2593-2605.

$101 \mathrm{X}$. Yao, Y. Zhao, F. A. Castro and L. Mai, ACS Energy Lett., 2019, 4, 771-778.
11 Z. Zhang, B. Xu and X. Wang, Chem. Soc. Rev., 2014, 43, 7870-7886.

12 J. Feng, C. Gao and Y. Yin, Nanoscale, 2018, 10, 20492 20504.

13 B. Jiang, Y. Guo, J. Kim, A. E. Whitten, K. Wood, K. Kani, A. E. Rowan, J. Henzie and Y. Yamauchi, J. Am. Chem. Soc., 2018, 140, 12434-12441.

14 B. Jiang, C. Li, Ö. Dag, H. Abe, T. Takei, T. Imai, M. S. A. Hossain, M. T. Islam, K. Wood, J. Henzie and Y. Yamauchi, Nat. Commun., 2017, 8, 3-4.

15 B. L. Nicole, L. Rozes and C. Sanchez, Adv. Mater., 2010, 22, 3208-3214.

16 C. Sanchez, L. Rozes, F. Ribot, D. Grosso, C. Sassoye, C. Boissiere and L. Nicole, Comptes rendus - Chim., 2010, 13, 339.

17 N. Kranzlin and M. Niederberger, Mater. Horizons, 2015, 2, 359-377.

18 Editorial, Nat. Commun., 2018, 9, 5268.

19 D. P. Debecker, S. Le Bras, C. Boissiere, A. Chaumonnot and C. Sanchez, Chem. Soc. Rev., 2018, 47, 4112-4155.

20 Spray Drying \& Encapsulation Solutions, https://www.buchi.com/en/content/spray-dryingencapsulation-solutions.

21 Spray Drying Plants, https://www.dorst.de/en/spray-dryingplants.html.

22 H. Hentze, S. R. Raghavan, C. A. Mckelvey and E. W. Kaler, Langmuir, 2003, 19, 1069-1074.

23 Y. Lu, H. Fan, A. Stump, T. L. Ward, T. Rieker and J. Brinker, Nature, 1999, 398, 223-226.

24 M. Faustini, M. Giraud, D. Jones, J. Rozière, M. Dupont, T. R. Porter, S. Nowak, M. Bahri, O. Ersen, C. Sanchez, C. Boissière, C. Tard and J. Peron, Adv. Energy Mater., 2018, 9, 1802136.

25 S. Park, G. D. Park, D. Ko, Y. C. Kang and Y. Piao, Chem. Eng. J., 2017, 315, 355-363.

26 A. G. Marquez, P. Horcajada, D. Grosso, G. Ferey, C. Serre, C. Sanchez and C. Boissiere, Chem. Commun., 2013, 49, 38483850.

27 Y. Lee, J. Suntivich, K. J. May, E. E. Perry and Y. Shao-Horn, J. Phys. Chem. Lett., 2012, 3, 399-404.

28 O. Kasian, J.-P. Grote, S. Geiger, S. Cherevko and K. J. J. Mayrhofer, Angew. Chemie Int. Ed., 2018, 57, 2488-2491.

29 A. Osaka, T. Takatsuna and Y. Miura, J. Non. Cryst. Solids, 1994, 178, 313-319.

30 Y.-B. Cho, A. Yu, C. Lee, M. H. Kim and Y. Lee, ACS Appl. Mater. Interfaces, 2018, 10, 541-549.

31 Q. Li, D. Liu, L. Xu, R. Xing, W. Liu, K. Sheng and H. Song, ACS Appl. Mater. Interfaces, 2015, 7, 22719-22726.

32 A. Yu, C. Lee, M. H. Kim and Y. Lee, ACS Appl. Mater. Interfaces, 2017, 9, 35057-35066.

33 S. J. Kim, Y. L. Kim, A. Yu, J. Lee, S. C. Lee, C. Lee, M. H. Kim and Y. Lee, Sensors Actuators, B Chem., 2014, 196, 480-488.

34 C. Boissiere, D. Grosso, A. Chaumonnot, L. Nicole and C. Sanchez, Adv. Mater., 2011, 23, 599-623.

35 N. Bestaoui and E. Prouzet, Chem. Mater., 1997, 9, 10361041.

36 T. Kashiwagi, J. E. Brown, A. Inaba, K. Hatada, T. Kitayama and E. Masuda, Macromolecules, 1986, 19, 2160-2168.

37 J. A. Chandrasiri, D. E. Roberts and C. A. Wilkie, Polym. Degrad. Stab., 1994, 45, 97-101.

38 R. S. Beer, C. A. Wilkie and M. L. Mittleman, J. Appl. Polym. Sci., 1992, 46, 1095-1102.

39 A. Grozavu, H. B. Hepburn, P. J. Smith, H. K. Potukuchi, P. J. Lindsay-Scott and T. J. Donohoe, Nat. Chem., 2019, 11, 242 247.

40 C. Yuan and B. Liu, Org. Chem. Front., 2018, 5, 106-131.

41 R. Della Pergola and L. Garlaschelli, J. Organomet. Chem., 1987, 331, 271-274. 
42 R. Psaro, D. Roberto, R. Ugo, C. Dossi and A. Fusi, J. Mol. Catal., 1992, 74, 391-400.

43 C. B. Godiya, S. Gabrielli, S. Materazzi, M. S. Pianesi, N. Stefanini, E. Marcantoni, J. Environ. Manage. 2019, 231, 1012-1020.

44 B.-S. Kang, S. G. Kim, J.-S. Kim, J. Anal. Appl. Pyrolysis 2008, 81, 7-13.

45 A. C. Ferrari and J. Robertson, Phys. Rev. B, 2000, 61, 1409514107.

46 S. A. Sherif, M. S. Abdel-Halim, S. M. El-Marsafy and M. H. ElSayed, J. Eng. Appl. Sci., 2003, 50, 587-602. 